\title{
Thermodynamic Performance Study on the 600 MW Direct Air-Cooled Power Plant
}

\author{
Hongbin Zhao ${ }^{1,2}$, Lina Che ${ }^{1,2}$, Chang Liu ${ }^{1,2}$ \\ ${ }^{1}$ College of Machinery and Transportation Engineering, China University of Petroleum, Beijing, China \\ ${ }^{2}$ Beijing Key Laboratory of Process Fluid Filtration and Separation, Beijing, China \\ Email: hbzhao@cup.edu.cn, selinache@foxmail.com
}

How to cite this paper: Zhao, H.B. Che, L.N. and Liu, C. (2017) Thermodynamic Performance Study on the 600 MW Direct Air-Cooled Power Plant. Energy and Power Engineering, 9, 332-353.

https://doi.org/10.4236/epe.2017.96023

Received: April 26, 2017

Accepted: June 20, 2017

Published: June 26, 2017

Copyright $\odot 2017$ by authors and Scientific Research Publishing Inc. This work is licensed under the Creative Commons Attribution International License (CC BY 4.0).

http://creativecommons.org/licenses/by/4.0/

c) (7) Open Access

\begin{abstract}
We established the thermodynamic analysis model by using the actual measurement parameters of $600 \mathrm{MW}$ direct dry cooling power plant in Wuxiang, China. The performance, especially the exergy losses of the unit as well as its subsystems mainly including seven parts were obtained not only at one specific load but also at different loads. We have found that the exergy loss in the boiler is usually more than $70 \%$ of the total exergy loss of the system, while the exergy loss of the combustion occupies greater than $50 \%$ of that of the boiler. Therefore, it is crucial to reduce the losses in the boiler for energy saving potential improvement, especially that of the combustion and heat transfer. At the same time, the cold end optimization has relatively large potential for energy saving due to that the exergy efficiency of the air cooling system is quite low being about $5.7 \%$ or so. In addition, we have gotten the main changing trends of system performances along with the load change, including exergy loss, exergy efficiency and coal consumption, which were derived from the real-time system performance statistics according to a large amount of measured data in real time. In order to make the whole system run more efficiently, it is advised that the unit should run at the load better than 350 MW.
\end{abstract}

\section{Keywords}

Exergy Analysis, Exergy Loss, Exergy Efficiency, Specific Operating Condition, Load Variation

\section{Introduction}

Thermal power plants combining the coal-burned boiler and steam turbine have been developing toward superpower, high parameters, energy saving and environment friendly. The operation of the power plant is a complex process with 
characteristics of nonlinearity, time-variant, multi-loop coupling. Moreover, the analysis of the variation law of the thermodynamic process and the loss distribution is the key to the correlational researches, such as the operation optimization, control assessment, fault diagnosis and analog simulation [1] [2] [3]. Therefore, the study on the total processes of the thermal power plant about energy input, release, transmission and conversion will have very important significance for the research on the system optimization operation.

Recently, a lot of scholars have carried out related studies on coal-fired power plant from different aspects. In order to improve the performance of coal-fired power plants, including the control of pollutants, numerous studies have been conducted. Advanced self-learning controller has been developed and the effects of advanced control concept on combustion process have been analyzed using artificial neural-network based parameter prediction model, but they have not analysed the results during real time thermal power plant operation [4]. Bastian Hoffmann, etc. have developed the appropriate approach to analyse impacts of climate change on cooling systems and power plant efficiency by modeling selected German thermal power plant units and their respective cooling systems through dynamic simulation taking into account legal thresholds for heat discharges to river water together with climate data projections. And the presented modeling approach can provide high temporal resolution and the detailed representation of site specific plant properties to support the planning of production and optimization of plant revisions [5]. In order to evaluate the power plant from a more comprehensive perspective, a multi-criteria assessment of the six different power plants is conducted through Analytic Network Process (ANP) with respect to technical and sustainability, economic applicability, quality of life and society Economic impact. [6]. In order to promote preventive maintenance as well as failure analysis while ensuring a degree of compliance with statutory regulations, a new methodology for short- and long-term assessment of the operation of a thermal power plant was proposed. It was focused on a new procedure for detection over different thermodynamic variables involved, without discussing thermal performance of the system, e.g., thermal efficiency, exergy efficiency as well as exergy destruction, and coal consumption, etc. [7]. An approach based on data envelopment analysis (DEA) and game theory has been introduced. They defined two categories of inputs (operational and non-operational) to measure performance of power plants located in Iran in order to evaluate decision making units (DMUs) regardless of their number by a large scale of measures in the competitive environment [8]. In allusion to a 50MWe solar thermal power plant, two different cooling technologies for it are compared from the exergetic viewpoint, mainly focusing on the exergy destruction, without considering the effect of different loads on the units' performances [9]. Taking coal-fired power plant as the research object, the relevant scholars also have conducted a lot of studies involving $\mathrm{CHP}, \mathrm{CO}_{2}$ capture and pollutants controlling, etc., the purpose is to in order to make this long-term used major power generation systems more highly efficient and more environmentally friendly 
[10] [11] [12] [13] [14]. The above investigations are mainly for the overall assessment of power plant performance, such as multi-criteria comprehensive assessment methods, on-site detection methods, network analysis and combined with environmental and economic aspects of comprehensive assessment methods. In addition, we also need to analyze the specific location and size of the energy loss, so as to make clear the distribution and loss of energy in the power plant.

Analysis of power generation systems are of scientific interest and also essential for the efficient utilization of energy resources. The most conventional method of constructing mathematics models based on the first law of thermodynamics is widely used to evaluate the performance of energy systems [15] [16] [17] [18]. The first law method does not account for the degradation or irreversibility of energy in the system. While the method of exergy analysis based on the second law of thermodynamics perfects the method of energy balance and gets down to research on the whole system from the higher level of the conservation and degradation of energy quality. Exergy analysis is a useful method to design, evaluate, optimize and improve thermal power plants, not only to determine the size, location and cause of plant irreversibility, but also to evaluate the performance of each component of the plant meaningfully. This analysis allows one to quantify the loss of efficiency in a process due to the loss in energy quality. Recently, there is increasing interest in the combined utilization of the first and second laws of thermodynamics, using such concepts as exergy and exergy destruction in order to evaluate the efficiency with which the available energy is consumed. It can be said that performing exergetic and energetic analyses together can give a complete depiction of system characteristics. Such a comprehensive analysis will be a more convenient approach for the performance evaluation and determination of the steps towards improvement [19] [20] [21] [22] [23]. For these reasons, the energy utilization analysis provides a true measure of power generation system performance.

In the literature, there exist a number of papers concerning energetic and exergetic performances of coal-fired thermal power plants. In allusion to coal fired power plants, mainly including regenerative-reheat Rankine cycle power plants, using subcritical, supercritical, and ultra-supercritical steam conditions, as well as nuclear steam power plants, the exergy analysis method was applied to determine the exergy losses and the exergy efficiency of the power plant as well as individual components [24]-[32]. In the published literature, not much is reported on the energy and exergy analysis of large-scale generator systems by combining live real-time measurement parameters. Exergy analysis can be used to go more into details of the plant to localize and quantify the exergy losses.

Undoubtedly, new efficient power cycle systems and technologies will continue to appear, however, the traditional thermal power plants using coal as the main fuels will continue to play an important role in electric power production field, especially in China, where the coal occupies the dominant position in the energy structure. The fundamental research of the traditional dominated ther- 
mal power system especially with the in-depth method has very important significance for comprehensive understanding of the operational mechanism of the energy system, thus, providing useful guidance for the efficient operation of the actual unit. In this paper, the comprehensive energy utilization analysis of the $600 \mathrm{MW}$ power plant is carried out mainly by using the actual running measurement data, especially under the specific and variable operating conditions, which reveals the concrete erergy loss and erergy efficiency of the system and its components. Thus the study can lay a solid foundation for the improvement of power plant performance.

\section{Description of the System and Analysis Methods}

\subsection{Description of the System}

As shown in Figure 1, the flow sheet of the thermodynamic system is established according to the practically running $600 \mathrm{MW}$ thermal power plant with the direct air cooling condenser in Wuxiang, China. From the perspective of research, the whole system is mainly divided into seven subsystems, including the boiler system, coal pulverizing system, fuel air system, steam turbine system, regenerative system, air cooling system and Power generation system, which have different functions respectively.

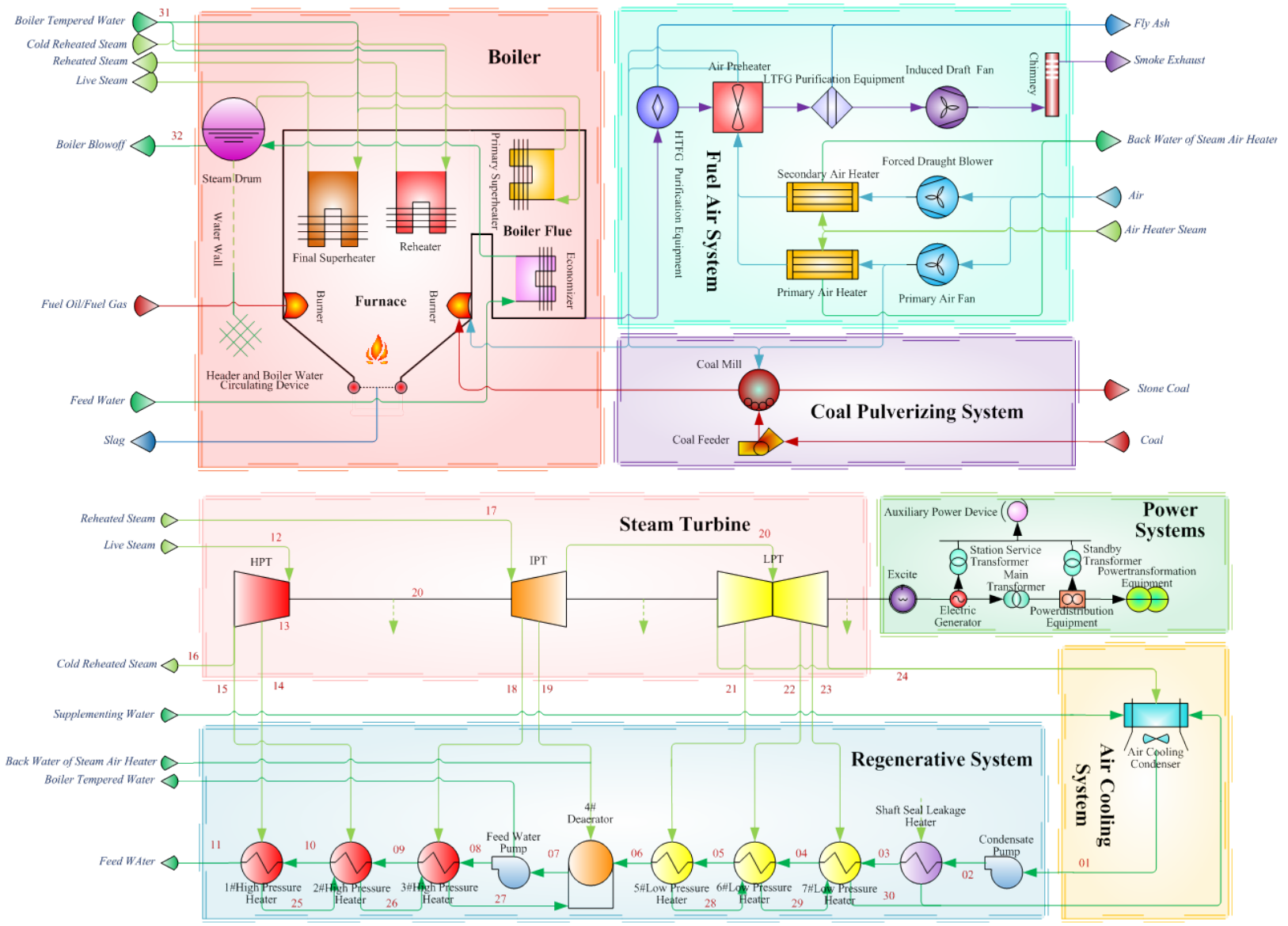

Figure 1. Flow sheet of the thermodynamic system. 
The main facilities contained in the boiler system are the economizer, superheater, reheater, steam dome, and the cooled water wall. Coal pulverizing system provides the physical preparation of coal satisfying the necessary standards for the combustion such as the physical parameter of particle size and humidity [33]. Before being transported into the boiler, the air absorbs heat from the smoke exhaust in the fuel air system to achieve a certain temperature [34]. Steam turbine system contains high pressure cylinder, medium-pressure cylinder and low pressure cylinder. In the regenerative system, different pressure steam extraction from different cylinder will heat the condensed water from the air cooling system in the corresponding heater respectively. Finally, the heated water whose temperature may be greater than $200^{\circ} \mathrm{C}$ as the feed water is pumped into the boiler, starting a new cycle working process, in which the coal burns and convert chemical energy to gas heat energy that realize heat transfer in different heat exchangers in turn.

\subsection{Energy and Exergy Analysis Methods}

The method of energy analysis based on the first law of thermodynamics is generally used to analyze power system performance. While the exergy analysis combining the first and the second law of thermodynamics is to probe the essence of the energy loss and the distribution of the available energy from the point of view of energy amount and energy quality, which reveals two things: the destruction of exergy within a system component as well as the exergetic efficiency showing how effectively the exergetic resources supplied to a component have been used.

In this paper, in order to evaluate the performance of the system synthetically, this paper uses the energy analysis method and the analysis method, and evaluates them with different evaluation indexes, such as thermal efficiency, efficiency, loss rate, loss rate and dissipation heat and net coal consumption. The exergy flow is shown in Figure 2, in which the red arrows represent the input and the output exergy of the system, black arrows the exchange exergy among the subsystems, and blue arrows the exergy losses for different process.

\section{Exergy Analysis Model}

\subsection{Assumptions}

In order to investigate the performance of the system by exergy analysis, some hypotheses are made as follows:

a) Ignoring the diffusion exergy loss of working medium in the pipelines and small leakage of working medium at equipment joints or connections.

b) Flow rates of liquid and solid mediums are from the measured data, and that of the gas medium from quality equilibrium calculation of system.

c) The working medium mixes uniformly on the condition of steady flow.

d) To ensure the reliability of the measured parameters, they must be examined and filtered before into model for calculation. 


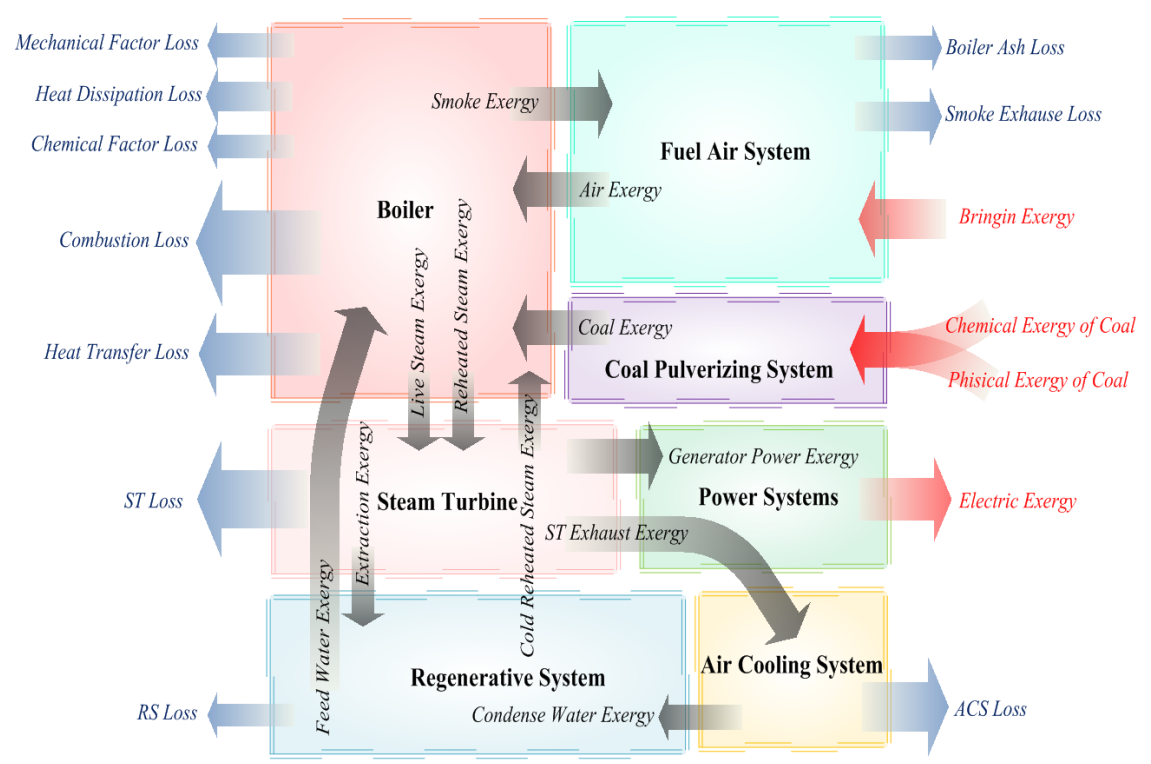

Figure 2. Diagram of the exergy flow.

e) The reference temperature is about $15^{\circ} \mathrm{C}$ and the reference pressure is about 1 atm for the exergy analysis.

\subsection{Model of the Exergy Loss}

In an exergy analysis, the heat rate does not have the same value as the power, and the loss of work equals to the difference between the input exergy and the output exergy of the system. According to energy and exergy balance, the loss can be described as:

$$
E X, \text { loss }=\sum E X_{\text {in }}-\sum E X_{\text {out }}
$$

where, $E X$, loss is the exergy loss; $\Sigma E X_{\text {in }}$ is the input exergy; $\Sigma E X_{\text {out }}$ is the output exergy.

The exergy in the system contains the exergy of steady flowing medium, the heat exergy, the chemical exergy of coal as fuel, and the mechanical exergy.

$$
E X_{\text {flow }}=\left(H-H_{0}\right)-T_{0} \cdot\left(S-S_{0}\right)+\frac{1}{2} M \cdot c^{2}+M \cdot g \cdot z
$$

where, $E X_{\text {flow }}$ is the exergy of steady flowing medium; $H, S$ are the enthalpy and entropy of the working medium at certain thermal state; while $H_{\infty} S_{o}$ are that at the environment state. Generally, it is assumed that the exergy due to kinetic energy and potential energy are negligible.

$$
E X_{Q}=Q-T_{0} \int_{1}^{2} \frac{\delta Q}{T}
$$

where, $E X_{Q}$ is the heat exergy; $Q$ is the heat energy; $T_{0}$ is the ambient temperature [35] [36] [37] [38], $K$.

$$
e X_{c, c h}=Q_{c, a r} \cdot\left(1.0064+0.1519 \frac{H_{a r}}{C_{a r}}+0.0616 \frac{O_{a r}}{C_{a r}}+0.429 \frac{N_{a r}}{C_{a r}}\right)
$$

where, $Q_{c, a r}$ is the low heat value of the as-received basis coal, kJ/kg; $C_{a r}, H_{a r}, O_{a r}$ 
$N_{a r}$ are the mass percentage of them in the as-received basis coal, \%; $e X_{c, c h}$ is the chemical exergy per unit mass of coal, $\mathrm{kJ} / \mathrm{kg}$.

$$
e x_{c, p h}=C_{c} \cdot\left[\left(T_{c}-T_{0}\right)-T_{0} \cdot \ln \frac{T_{c}}{T_{0}}\right]
$$

where, $C_{c}$ is the specific heat of the dry basis coal, $\mathrm{kJ} /(\mathrm{kg} \cdot \mathrm{K}) ; T_{c}$ is the temperature of the coal, $\mathrm{K} ; e x_{c, p h}$ is the physical exergy per unit mass of coal, $\mathrm{kJ} / \mathrm{kg}$.

$$
\text { ex, } \text { loss }_{s}=\left(V_{s} \cdot C P_{s}+V_{\mathrm{H}_{2} \mathrm{O}} \cdot C_{p \mathrm{H}_{2} \mathrm{O}}\right) \cdot\left[\left(T_{s}-T_{0}\right)-T_{0} \cdot \ln \frac{T_{s}}{T_{0}}\right]
$$

where, $T_{s}$ is the temperature of the smoke exhaust, $\mathrm{K} ; C_{\mathrm{pH}_{2} \mathrm{O}}$ is the average specific heat at constant pressure of the dry smoke from the temperature $T_{0}$ to $T_{s}$, $\mathrm{kJ} /\left(\mathrm{m}^{3} \cdot \mathrm{K}\right) ; V_{s}$ is the volume of the dry smoke coming from the combustion of unit mass coal, $\mathrm{m}^{3} / \mathrm{kg}$; ex, loss $_{s}$ is the exergy loss of the smoke exhaust, $\mathrm{kJ} / \mathrm{kg}$.

According to energy and exergy balance, the flow rate of the steam extraction can be calculated through the energy equilibrium matrix Equation (7), and then the exergy loss in the regenerative system can be got.

$$
\left[\begin{array}{cccccccc}
q_{1} & & & & & & \\
\gamma_{1} & q_{2} & & & & & \\
\gamma_{3} & \gamma_{3} & q_{3} & & & & \\
\gamma_{4} & \gamma_{4} & \gamma_{4} & q_{4} & & & \\
\tau_{5} & \tau_{5} & \tau_{5} & \tau_{5} & q_{5} & & \\
\tau_{6} & \tau_{6} & \tau_{6} & \tau_{6} & \gamma_{6} & q_{6} & \\
\tau_{7} & \tau_{7} & \tau_{7} & \tau_{7} & \gamma_{7} & \gamma_{7} & q_{7}
\end{array}\right]\left[\begin{array}{c}
D_{1} \\
D_{2} \\
D_{3} \\
D_{4} \\
D_{5} \\
D_{6} \\
D_{7}
\end{array}\right]=\left[\begin{array}{lllllll}
\tau_{1} & & & & & & \\
& \tau_{2} & & & & & \\
& & \tau_{3} & & & & \\
& & & & & & \\
& & \tau_{4} & & & \\
& & & \tau_{5} & & \\
& & & & \tau_{6} & \\
& & & & & & \tau_{7}
\end{array}\right]\left[\begin{array}{l}
D_{f w} \\
D_{f w} \\
D_{f w} \\
D_{c w} \\
D_{c w} \\
D_{c w} \\
D_{c w}
\end{array}\right](7)
$$

where, $i$ is the stage serial number, $q_{i}$ is the enthalpy drop at extraction stage $i$, $\mathrm{kJ} / \mathrm{kg} ; \gamma_{i}$ is the enthalpy drop of the drainage from the exheater in the current heater (No.i $), \mathrm{kJ} / \mathrm{kg} ; \tau_{i}$ is the enthalpy rise of the feed-water in the current heater (No.i), $\mathrm{kJ} / \mathrm{kg} ; D_{i}$ is the flow rate of the extraction stage $i, \mathrm{~kg} / \mathrm{s} ; D_{f w}$ is the flow rate of the feed-water, $\mathrm{kg} / \mathrm{s}$.

\subsection{Model of the Exergy Efficiency}

The calculation of the exergy efficiency can be expressed in different forms for the different facilities in the energy system. However, the description of them can be unified as the same form from the point of view of the principle of the exergy flow and the exergy efficiency that is the ratio of the exergy revenue and the exergy consumption in the thermodynamic process.

$$
\eta_{\text {ex }}=\frac{\sum W}{\sum E X_{\text {in }}-\sum E X_{\text {out }}}
$$

or

$$
\eta_{e x}=\frac{\sum E X_{\text {out }}-\sum E X_{\text {in }}}{\sum W}
$$

where, $\Sigma E X_{\text {in }}$ and $\Sigma E X_{\text {out }}$ are the input exergy and the output exergy respectively.

$$
\eta_{e x}=\frac{\Delta E X_{c}}{\Delta E X_{h}}
$$


where, $\Delta E X_{h}$ and $\Delta E X_{c}$ are separately the exergy difference of the high and low temperature heat source in the process of heat transfer.

\section{Results and Discussion}

According to the thermodynamic model established and the measured data, firstly, we have carried out the key study on the exergy loss of the system, and then obtained the trends of exergy loss and exergy efficiency with load variation. Although the errors and residuals may exist upon the individual measured data because of the uncertainty of the actual measurement and the factors due to the uncontrollability in the actual operation, the performance variation trend is reliable based on large measurement data. Coal is the supply fuel of the power plant, with the following components: moisture $=6.00 \%$, ash $=31.84 \%$, hydrogen $=3.23 \%$, nitrogen $=0.71 \%$, sulphur $=2.51 \%$, oxygen $=2.80 \%$, carbon $=$ $53.27 \%, \mathrm{GCV}=20350.00 \mathrm{~kJ} / \mathrm{kg}$.

\subsection{Performance Analysis at the Specific Operating Condition}

Based on the parameters of each stream in the Figure 1, as shown in Table 1, the values of the exergy loss and its proportion in the total exergy loss, as well as the exergy efficiency at $470 \mathrm{MW}$ are shown in Table 2. We get that the exergy loss of the total system is about $1111.41 \mathrm{MW}$, and the exergy efficiency is $30.75 \%$ or so.

Figure 3 shows the specific values of the exergy loss and its ratio for the main facilities in the whole system. We can see that the main parts of the exergy loss focus on the boiler, air cooling system and the steam turbine. Meanwhile, the

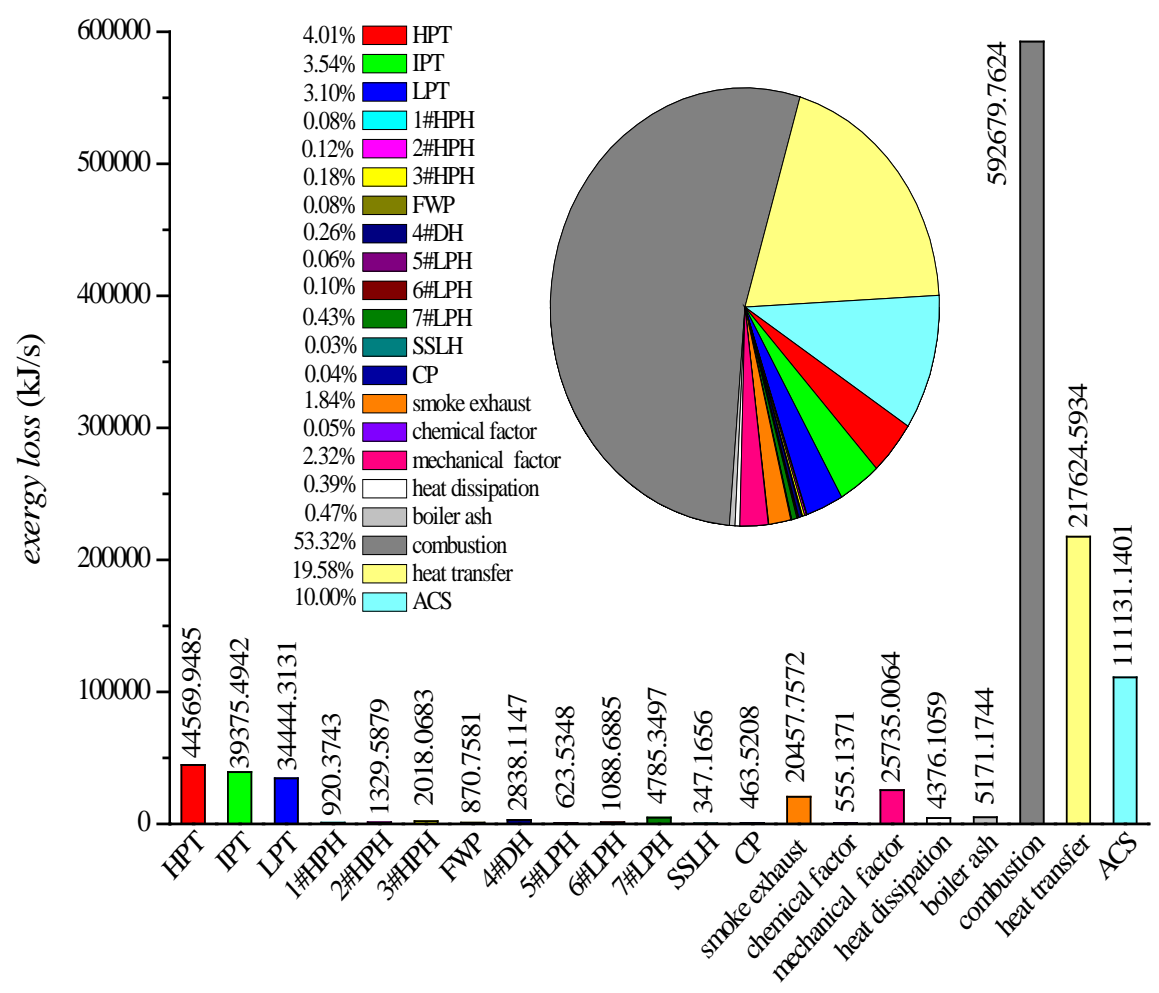

Figure 3. Exergy loss of the facilities at $470 \mathrm{MW}$. 
Table 1. Stream data of the system at $470 \mathrm{MW}$.

\begin{tabular}{|c|c|c|c|c|c|}
\hline State Point & $\begin{array}{c}T \\
(\mathrm{~K})\end{array}$ & $\begin{array}{c}P \\
(\mathrm{MPa})\end{array}$ & $\begin{array}{c}G \\
\left(\mathrm{~kg} \cdot \mathrm{s}^{-1}\right)\end{array}$ & $\begin{array}{c}h \\
\left(\mathrm{~kJ} \cdot \mathrm{kg}^{-1}\right)\end{array}$ & $\begin{array}{c}s \\
\left(\mathrm{~kJ} \cdot \mathrm{kg}^{-1} \cdot \mathrm{K}^{-1}\right)\end{array}$ \\
\hline 1 & 321.92 & 0.1162 & 1188.81 & 204.2931 & 1.8782 \\
\hline 2 & 321.71 & 1.3837 & 1188.81 & 204.5172 & 1.8455 \\
\hline 3 & 323.15 & 1.0887 & 1188.81 & 210.1440 & 1.0323 \\
\hline 4 & 366.54 & 0.7935 & 1188.81 & 391.8010 & 1.2313 \\
\hline 5 & 385.72 & 0.7223 & 1188.81 & 472.6615 & 1.4465 \\
\hline 6 & 399.17 & 0.7038 & 1182.14 & 529.7281 & 1.5919 \\
\hline 7 & 434.41 & 1.2711 & 1488.16 & 681.4119 & 1.9546 \\
\hline 8 & 438.13 & 18.3161 & 1414.48 & 707.4736 & 1.9714 \\
\hline 9 & 468.34 & 18.1118 & 1414.48 & 838.3713 & 2.2607 \\
\hline 10 & 502.86 & 18.0942 & 1414.48 & 992.5161 & 2.5783 \\
\hline 11 & 530.68 & 18.4342 & 1414.48 & 1122.1232 & 2.8307 \\
\hline 12 & 811.08 & 16.5057 & 1414.48 & 3421.2908 & 6.4850 \\
\hline 13 & 747.42 & 8.5453 & 1414.48 & 3337.4615 & 6.5103 \\
\hline 14 & 650.57 & 4.4476 & 102.26 & 3138.1523 & 6.5934 \\
\hline 15 & 587.22 & 2.7412 & 126.26 & 3022.2139 & 6.6119 \\
\hline 16 & 592.10 & 2.7958 & 1306.34 & 3032.0569 & 6.6210 \\
\hline 17 & 800.42 & 2.5391 & 1311.45 & 3525.5447 & 7.3833 \\
\hline 18 & 717.58 & 1.3530 & 66.29 & 3331.3186 & 7.3963 \\
\hline 19 & 615.54 & 0.6000 & 76.62 & 3133.1701 & 7.4443 \\
\hline 20 & 529.16 & 0.5641 & 1182.66 & 2939.9280 & 7.4744 \\
\hline 21 & 518.37 & 0.1543 & 31.75 & 2877.7175 & 7.5258 \\
\hline 22 & 476.48 & 0.0874 & 39.32 & 2801.1082 & 7.5680 \\
\hline 23 & 436.38 & 0.0280 & 31.62 & 2786.2092 & 7.7292 \\
\hline 24 & 321.80 & 11.0762 & 1038.93 & 2604.1462 & 7.9518 \\
\hline 25 & 505.10 & 2.9371 & 79.72 & 1200.0100 & 3.6295 \\
\hline 26 & 474.99 & 1.6413 & 170.57 & 1061.8300 & 3.3506 \\
\hline 27 & 446.28 & 0.8620 & 229.40 & 932.2800 & 3.0712 \\
\hline 28 & 387.29 & 0.1658 & 31.75 & 678.6100 & 2.4635 \\
\hline 29 & 369.57 & 0.0889 & 71.07 & 602.9700 & 2.2637 \\
\hline 30 & 330.42 & 0.0176 & 143.73 & 439.2500 & 1.7951 \\
\hline 31 & 439.79 & 8.3977 & 356.25 & 714.3224 & 2.0050 \\
\hline 32 & 628.59 & 17.3912 & 6.45 & 1652.0123 & 3.7493 \\
\hline
\end{tabular}

exergy loss of the regenerative system is quite little comparatively which just about 15.29 MW, and the ratio of the exergy loss about 1.38\%, among which the exergy loss of the low pressure heater No. 7 is relatively large, and that of the other heaters is very little and the ratio of the exergy loss of them is less than $0.5 \%$ of the whole system. 
Table 2. Results of the exergy analysis at $470 \mathrm{MW}$.

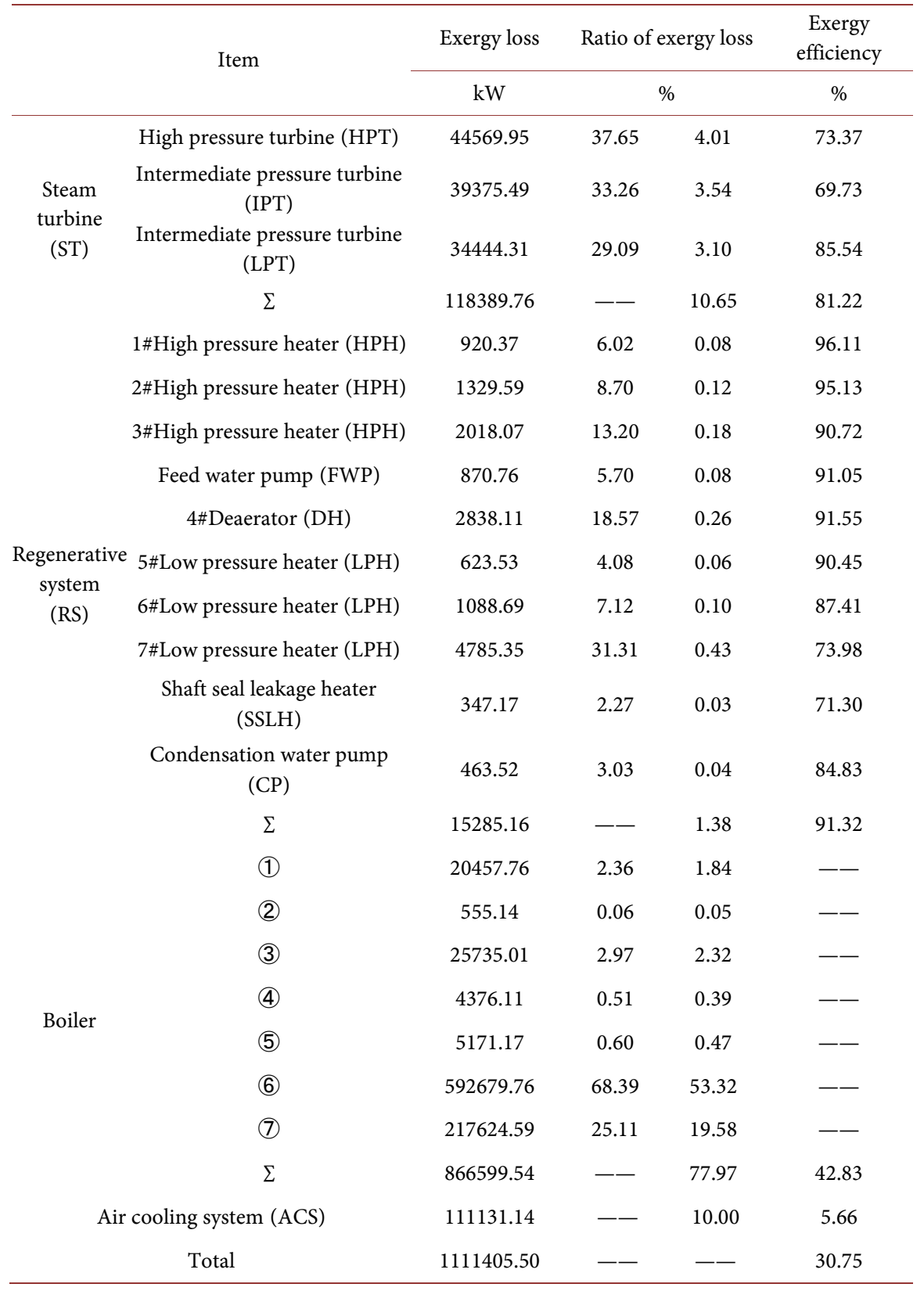

(1) smoke exhaust, (2) chemistry factor, (3) machinery factor, (4) heat dissipation, (5) boiler ash, (6) combustion, (7) heat transfer.

The distribution of the exergy loss of the main four subsystems is shown in Figure 4. The exergy loss of the boiler system is the largest which is about 866.60 MW and the exergy efficiency is about $42.83 \%$ with the ratio of the exergy loss $77.97 \%$ or so. The exergy losses of the steam turbine and the air cooling system are almost the same, which are about 118.39 MW and 111.13 MW respectively with the ratio of the exergy loss $10.65 \%$ and $10.00 \%$ or so. Nevertheless, the exergy efficiencies of them differ greatly, which are about $81.22 \%$ and $5.66 \%$ respectively. The exergy efficiency of the steam turbine is second to that of the regenerative system which is about $91.32 \%$, meanwhile the exergy efficiency of 


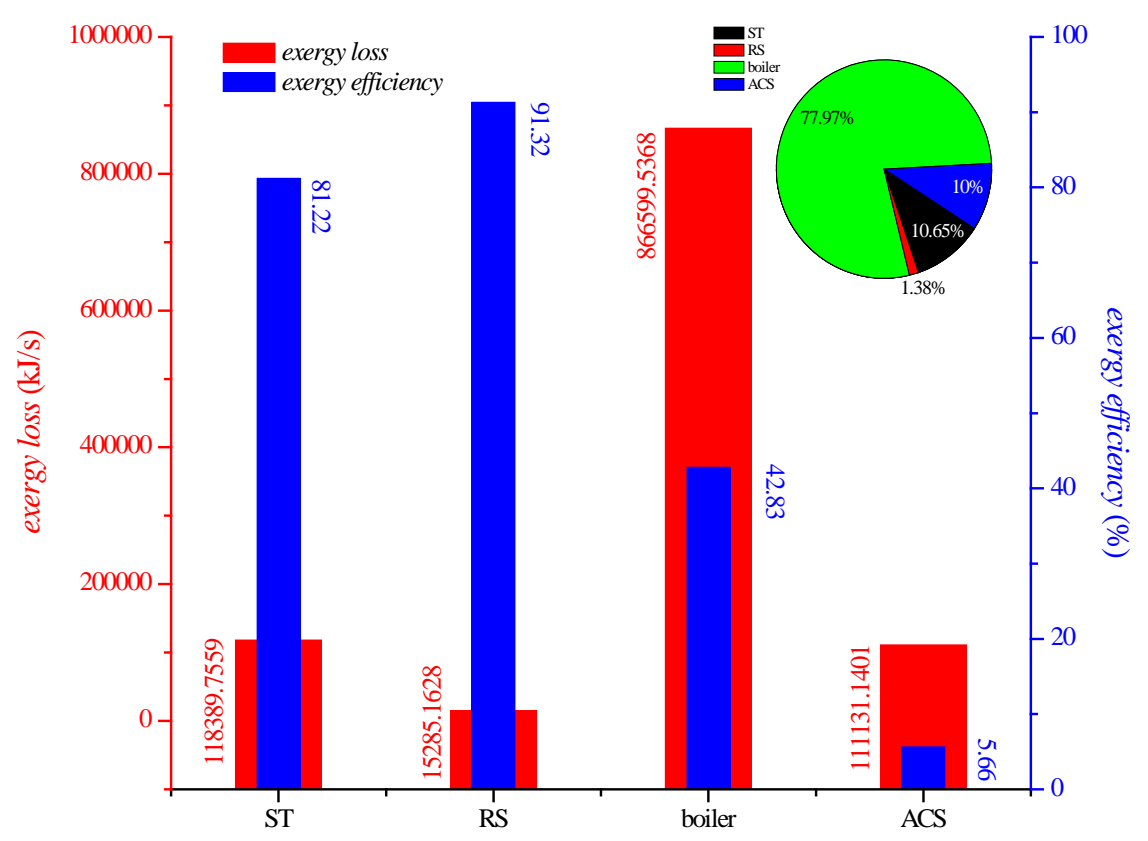

Figure 4. Exergy analysis of every subsystem.

the air cooling system is the lowest in the whole system. Therefore, we can see that the main energy saving potential is in boiler as well as the air cooling system.

Especially, the detailed exergy loss of the boiler is shown in Figure 5. We can see that the combustion exergy loss which is about 592.68 MW occupies the great proportion in the boiler system, about $68.39 \%$; the heat transfer exergy loss takes the second place which shows $217.62 \mathrm{MW}$ and $25.11 \%$ approximately. The every other exergy loss including machinery factor, the chemistry factor, the smoke exhaust, the heat dissipation, and the fly ash is less than $3 \%$ in the boiler system. Therefore, the key for the energy saving of the boiler is to decrease the exergy loss of the combustion and the heat transfer.

\subsection{Performance Analysis for Different Load Conditions}

In order to investigate the comprehensive performance of the system, it's necessary to precede the exergy analysis of the system at various loads, which is always changing all the time in actual operation. According to measured data of the power plant in practical running, we have gotten the variation laws of exergy, exergy loss as well as exergy efficiency.

Figure 6 shows the exergy variation of the live steam, the cold reheat steam, the reheated steam, the exhaust steam of the Intermediate pressure turbine (IPT) and the exhaust steam of the steam turbine. We can see that all the exergy mean value of them will increase with the load increment, nearly linear increasing, and that of the live steam is the largest increase, the exhaust steam of the steam turbine the minimum. As the load increases, the required main steam flow increases, resulting in an increase in the corresponding flow, so that the exergy of each steam increases. In addition, apart from the $5 \#$ and $6 \#$ Low pressure heater 


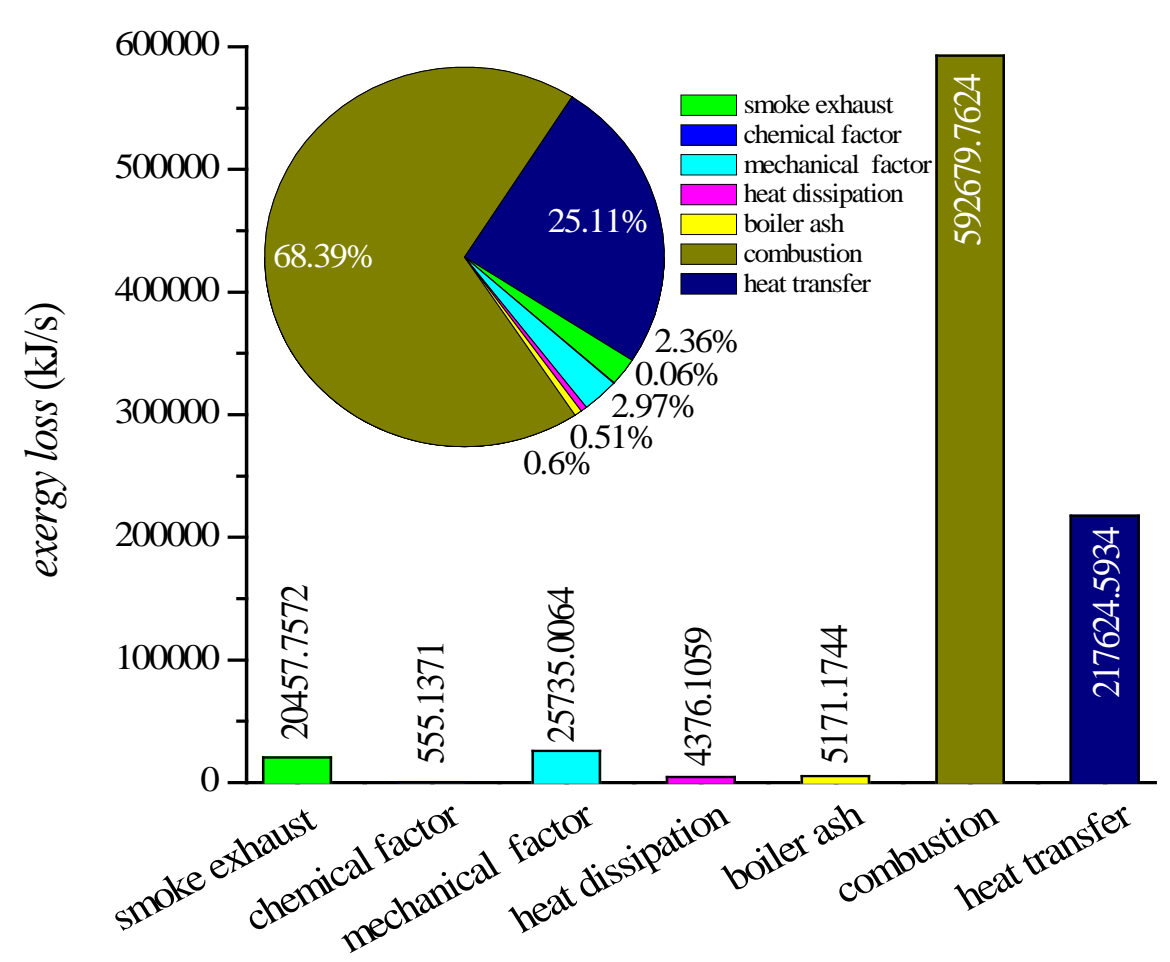

Figure 5. Exergy loss of the boiler.

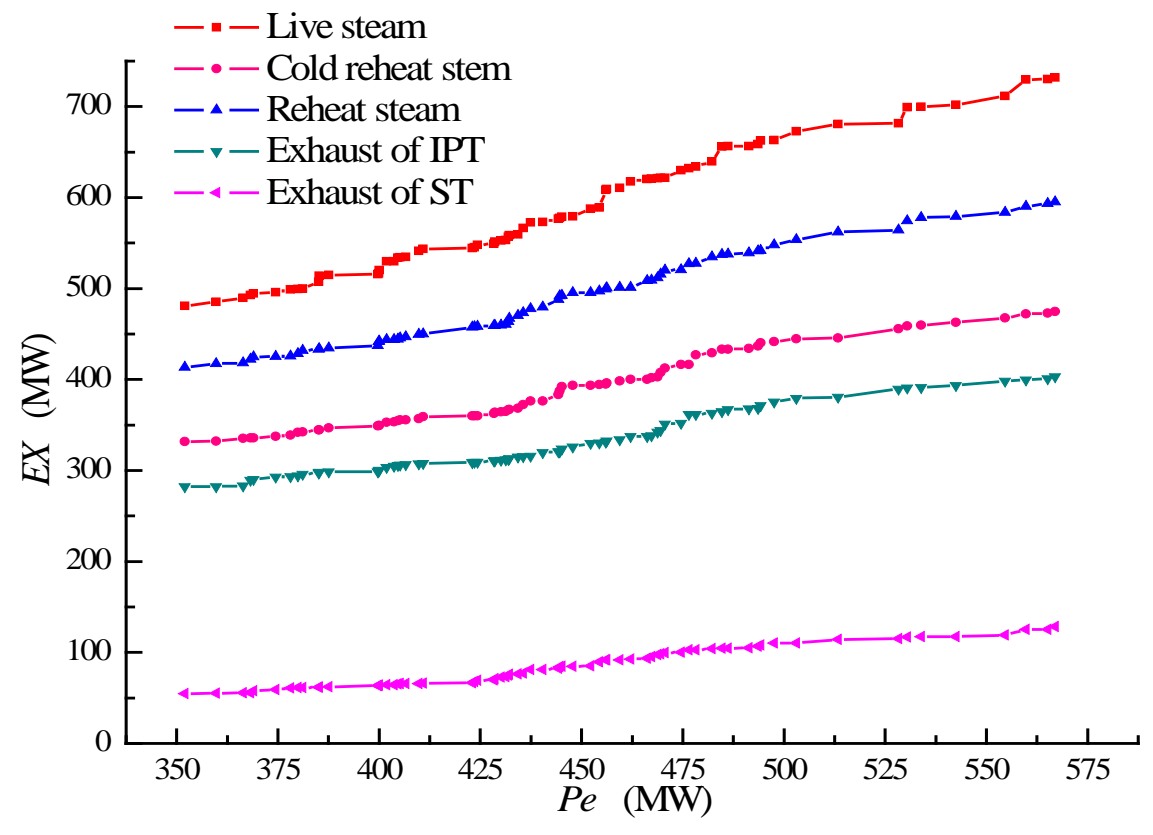

Figure 6. Exergy of the main steam flow.

(LPH), the average exergy of every extraction increases with load increase as shown in Figure 7. To analyze the cause of this variation, we know that with the load increases, the amount of condensed water that needs to be heated increases, and the corresponding low-temperature heat increases. Therefore, we need to increase the exergy of 7\# LPT, while to reduce the 5\# and 6\# extraction heat appropriately. 


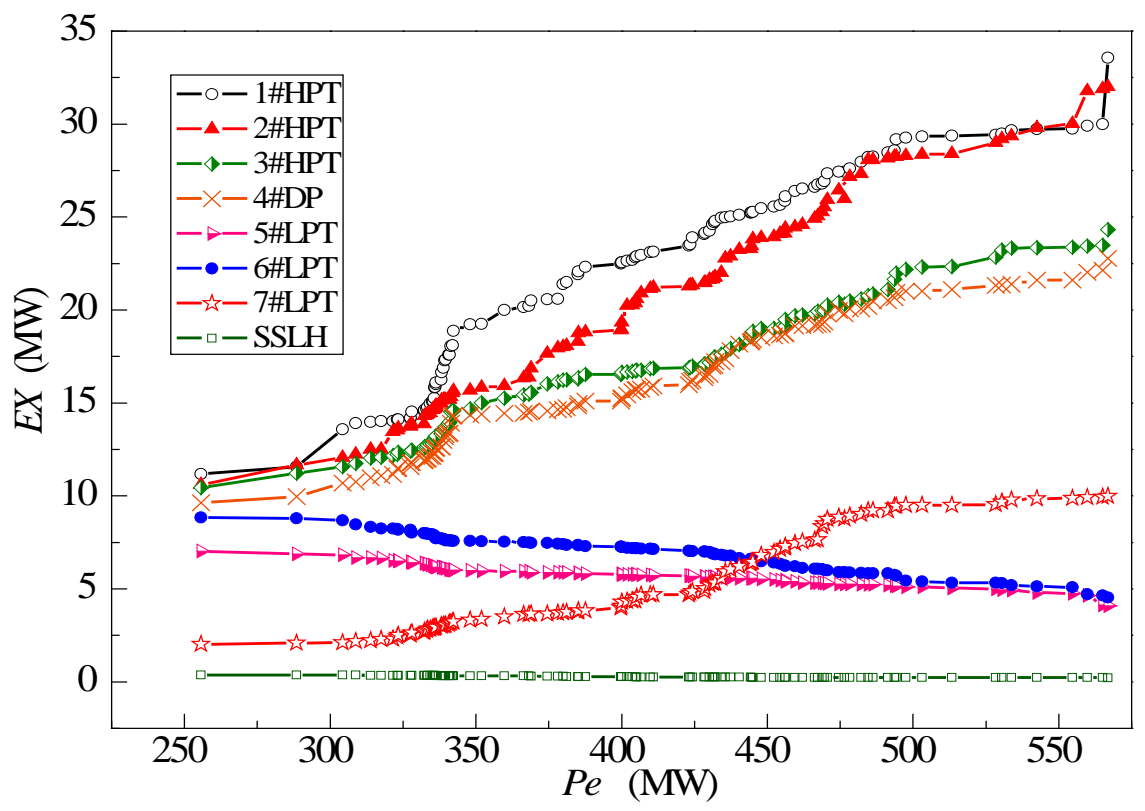

Figure 7. Exergy of the steam extraction.

The exergy loss as well as its ratio of the main four parts with load variation is shown in Figure 8. We can see that the exergy loss of the boiler system is always the maximal for the value, and the second the steam turbine and the air cooling system, and the minimum the regenerative system, and we find that the ratio of the exergy loss of the steam turbine and the regenerative system rises with the increase of the load, while that of the boiler system slowly rises first, then reduces. With the load increases, the exergy loss of combustion and heat transfer decreases, which accounts for most of the exergy loss in the boiler, resulting in a gradual decrease in energy loss at the boiler. In addition, the variation of the ratio of the exergy loss for the air cooling system is inconspicuous and is affected by multifarious factors such as environmental parameters, fan operation parameters, and so on. The exergy efficiency of the steam turbine as well as its three cylinders is shown in Figure 9. Due to the measured parameters fluctuate at low load, so we can see that the exergy efficiency of the three cylinders fluctuates relatively obviously at low load, generally less than $350 \mathrm{MW}-400 \mathrm{MW}$. Because the use of the nozzle adjustment method, it is obvious that the exergy efficiency of the high pressure cylinder averagely appears decreasing with the load increase and when the load rises approximately from $400 \mathrm{MW}$ to $560 \mathrm{MW}$, its efficiency increases from about $70 \%$ to $78 \%$. The exergy efficiency of the whole steam turbine with load changing, between about $80 \%$ and $85 \%$, is closely related with every cylinder, and the minimum value exists around $300 \mathrm{MW}$ to $350 \mathrm{MW}$. Therefore, the unit should be kept away from low load from the point of view of economy or safety.

As shown in Figure 10, the exergy efficiency of the boiler increase obviously with the load increment, e.g., when the load increases from $350 \mathrm{MW}$ to $550 \mathrm{MW}$, the exergy efficiency changes from $33.8 \%$ to $46.4 \%$, about 6 percent points increment per $100 \mathrm{MW}$ increment. In addition, we can see that the major exergy 


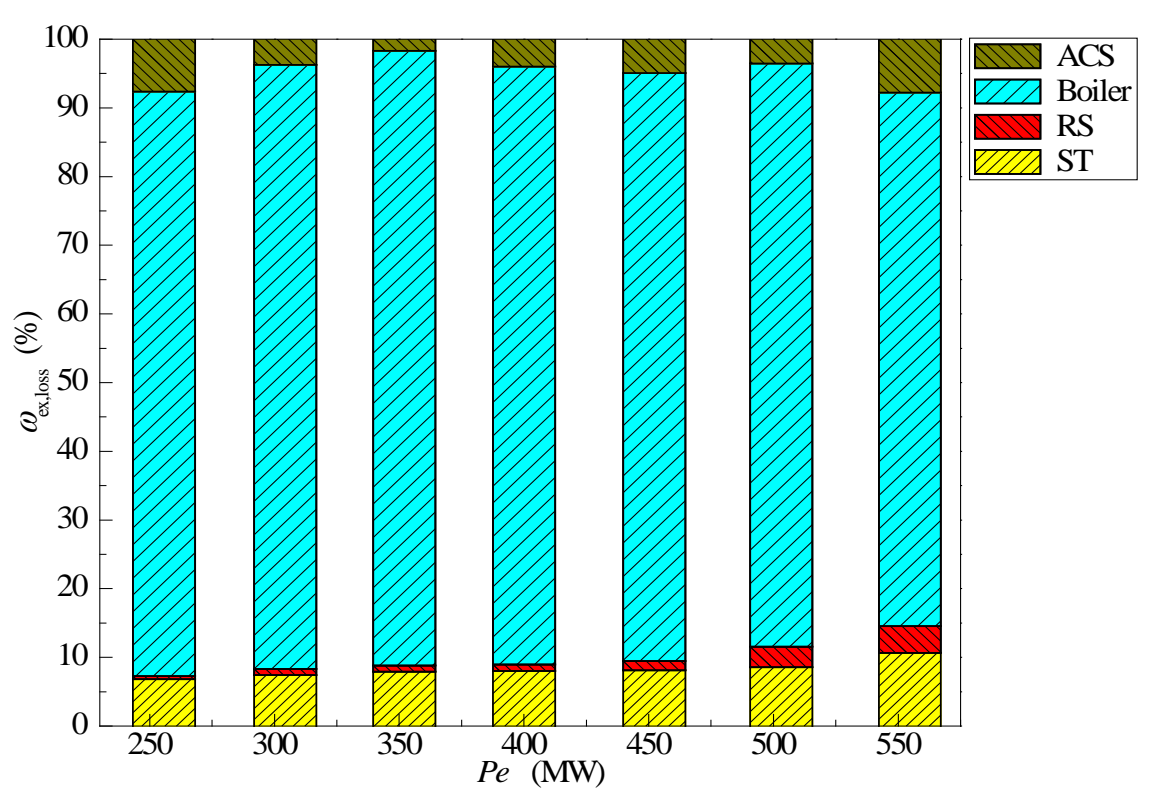

(a)

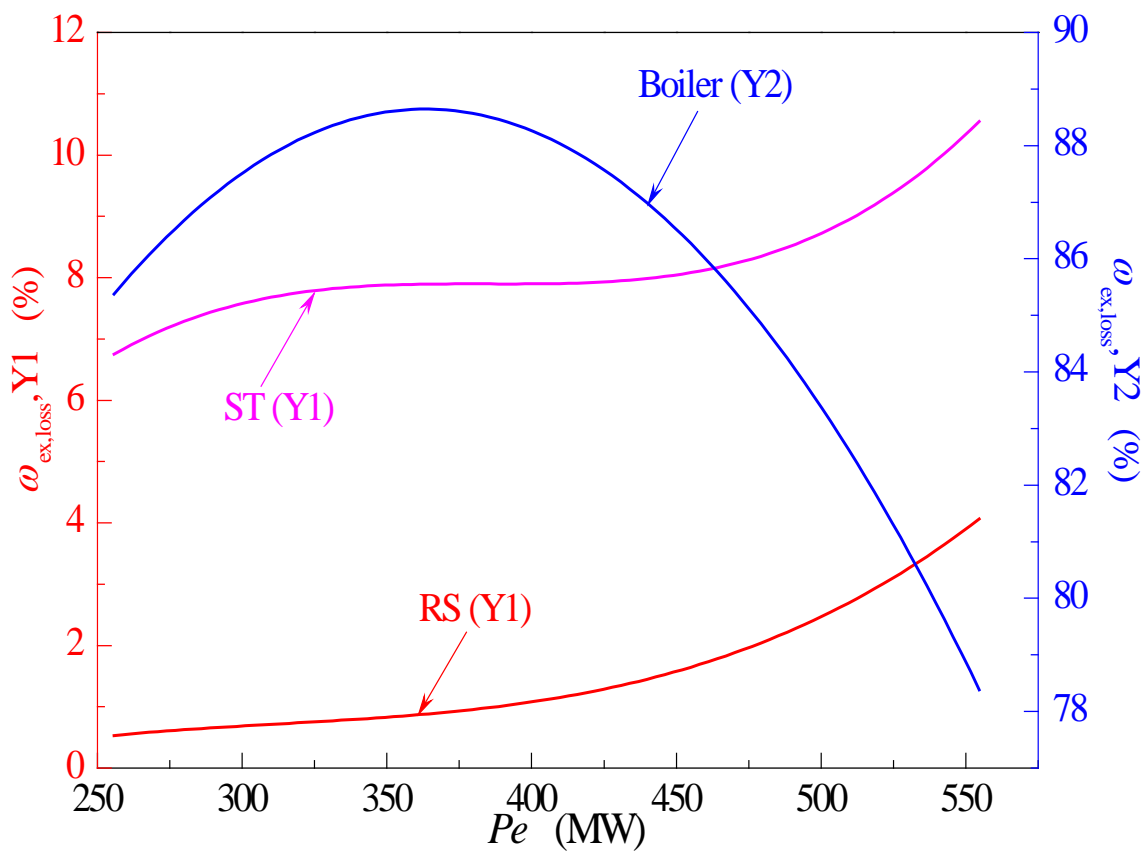

(b)

Figure 8. Ratio of exergy loss of the subsystems. (a) The distribution of the exergy loss ratio of the systems; (b) the trend of the exergy loss ratio with load.

losses in the boiler are from the combustion and the heat transfer, whose average values decrease with the load increment, while the heat transfer exergy loss decrease gently, and the combustion exergy loss drops obviously when the load is more than $500 \mathrm{MW}$, with exergy loss about $150 \mathrm{MW}$ from $500 \mathrm{MW}$ to $550 \mathrm{MW}$ or so. Because the coal combustion is more adequate at high load and the average temperature difference is reduced, the exergy loss of combustion and heat transfer decreases with increasing load. Additionally, we also see that even at the high load, the efficiency of the boiler is not better than $55 \%$, so that the im- 


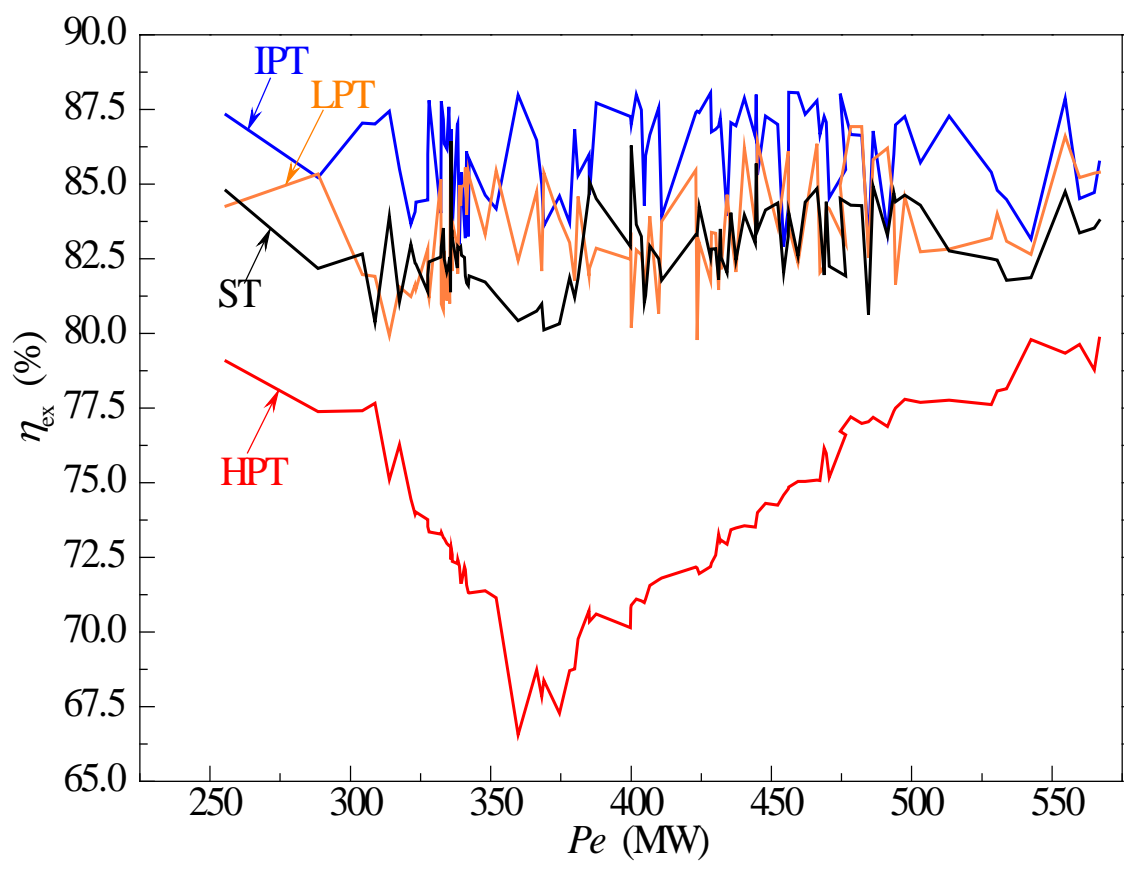

Figure 9. Exergy efficiency of the steam turbine.

provement of combustion and maintain the boiler running at high load as far as possible are crucial for boiler performance enhancement.

Figure 11 shows the variation of the total exergy loss and the exergy efficiency of the whole system with the load changing. The total exergy loss decreases slowly at the load less than about $500 \mathrm{MW}$ and decreases sharply at the load more than $500 \mathrm{MW}$ or so with load rising, e.g., the former, dropping about 20 MW with the load increment about $300 \mathrm{MW}$, and the latter, decreasing from $1100 \mathrm{MW}$ to $900 \mathrm{MW}$ with the load increasing from $510 \mathrm{MW}$ to $560 \mathrm{MW}$, which is similar to that of the boiler aforesaid. The increase of the total exergy efficiency is even uniform with the load rising. The total exergy efficiency increases from about $20 \%$ to $40 \%$ when the load varies from $250 \mathrm{MW}$ to $550 \mathrm{MW}$. From above, we can see that reduction of the boiler combustion exergy loss is of importance for the energy saving and the rational energy utilization, meanwhile, the operation at high load is an effective way to improve the performance of the thermal power system because the system parameters' matching is more reasonable with the increase of load.

In addition to the exergy analysis, according to the common indexes generally used in power plant, we have also obtained the heat and net coal consumption change with the load increment, as shown in Figure 12. Because the system exergy efficiency increases with increasing load, the amount of coal consumed by the unit power will be reduced, we can see that the heat and net coal consumption have similar decreasing trend with load increment. When the load is less than 330MW or so, the heat and net coal consumption increases fast with the load decreasing, e.g., with the load decreasing from $320 \mathrm{MW}$ to $260 \mathrm{MW}$, the heat and net coal consumption increases from $10098.2 \mathrm{~kJ} \cdot \mathrm{kW}^{-1} \cdot \mathrm{h}^{-1}$ to $11226.1 \mathrm{~kJ} \cdot \mathrm{kW}^{-1} \cdot \mathrm{h}^{-1}$, and from $376.1 \mathrm{~g} \cdot \mathrm{kW}^{-1} \cdot \mathrm{h}^{-1}$ to $428.2 \mathrm{~g} \cdot \mathrm{kW}^{-1} \cdot \mathrm{h}^{-1}$, respectively. Adversely, with the load 


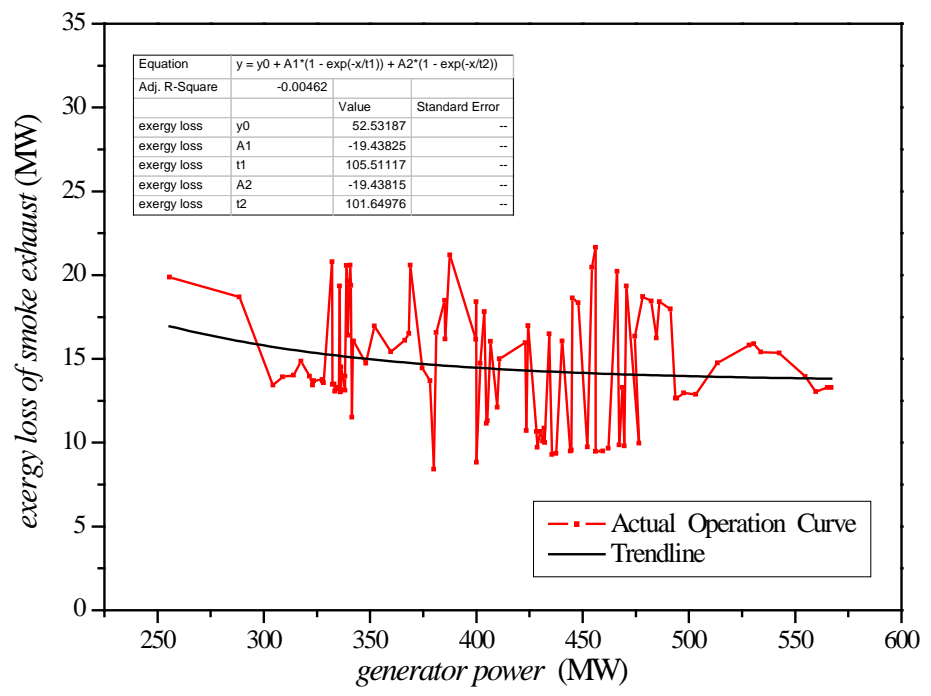

(a)

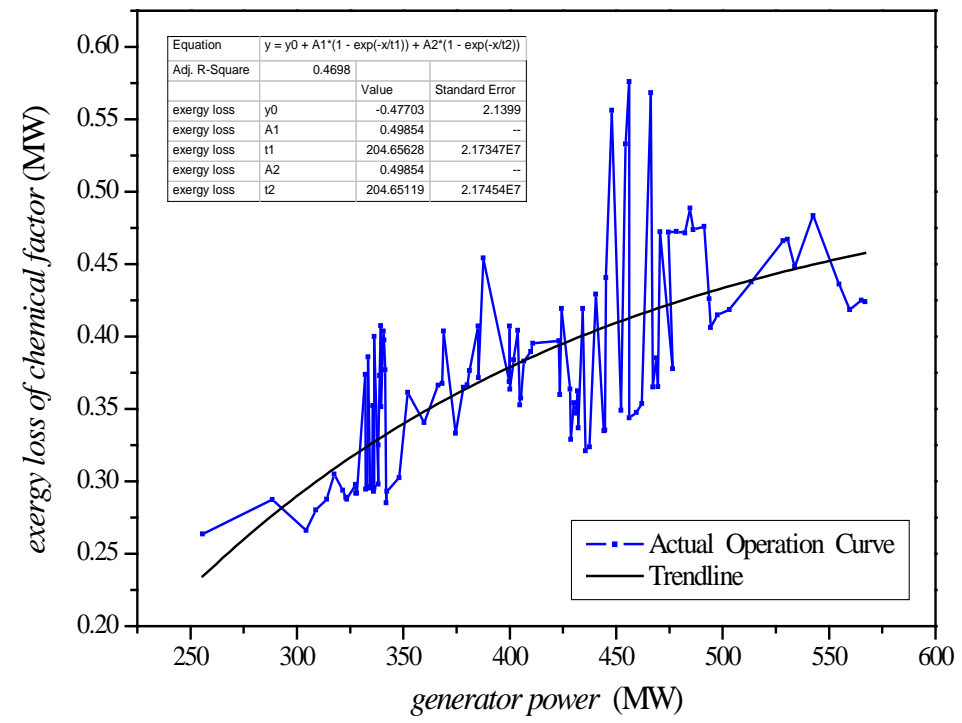

(b)

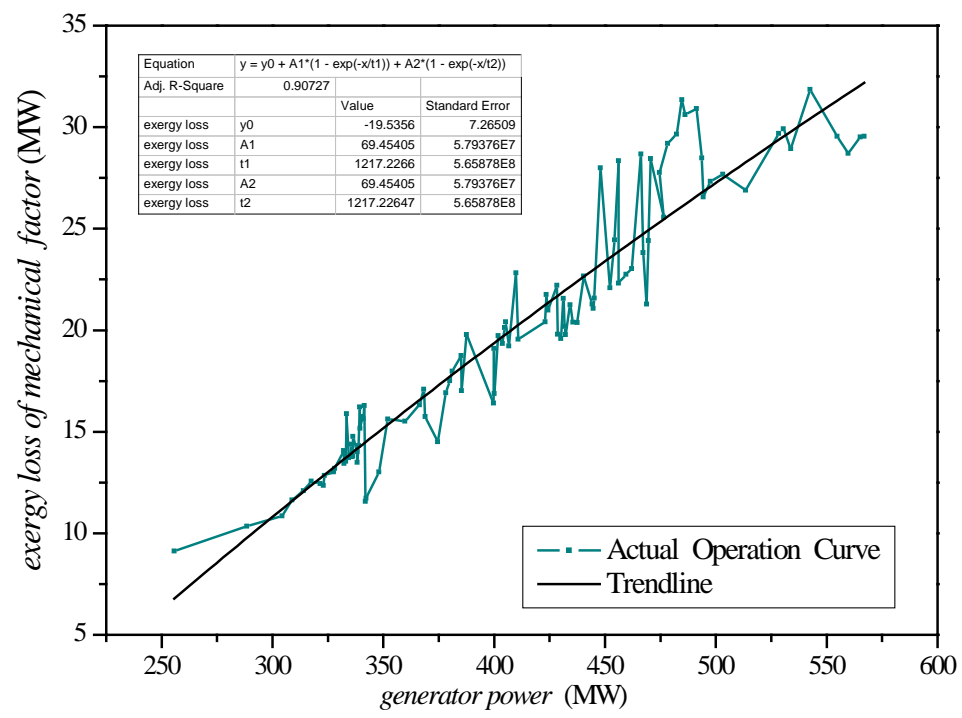

(c) 


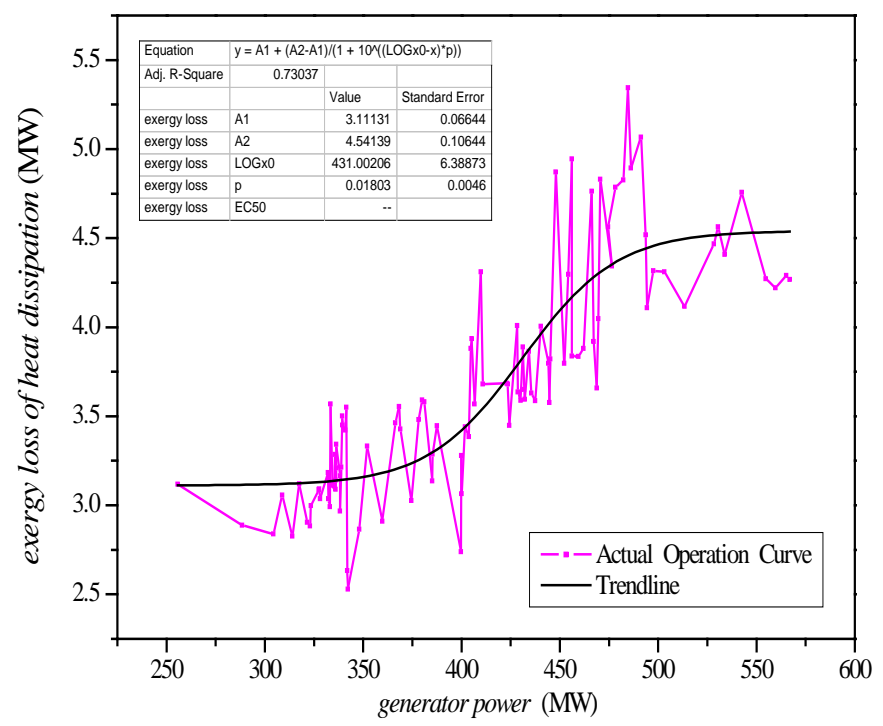

(d)

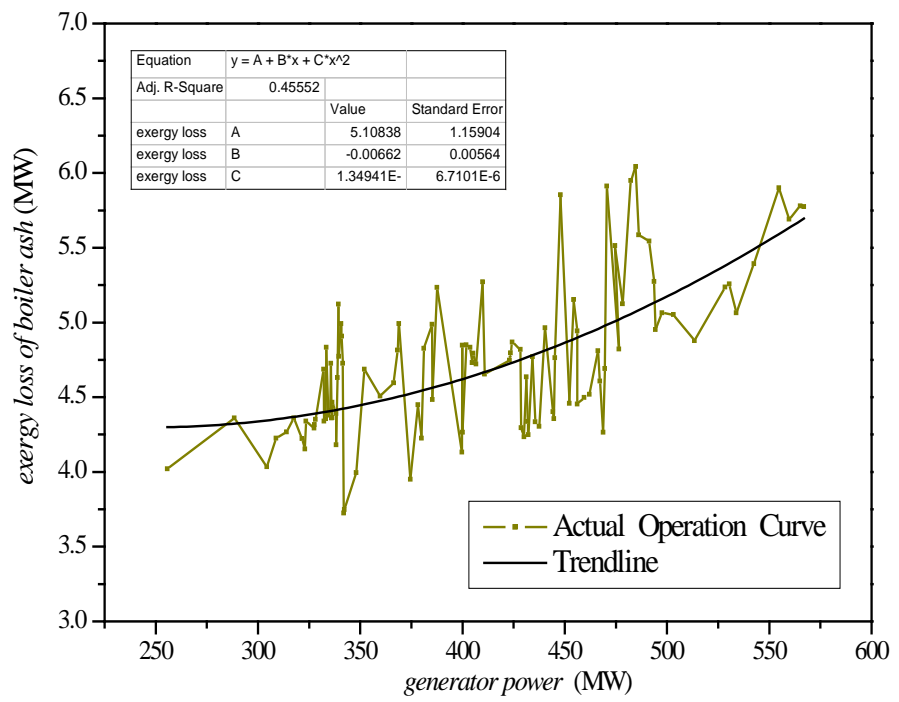

(e)

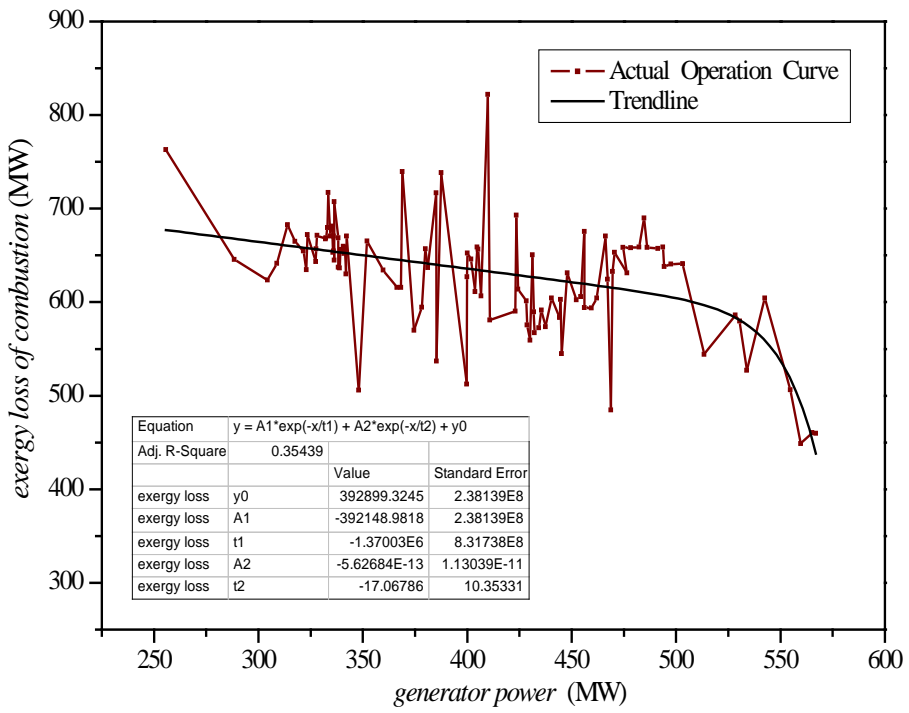

(f) 


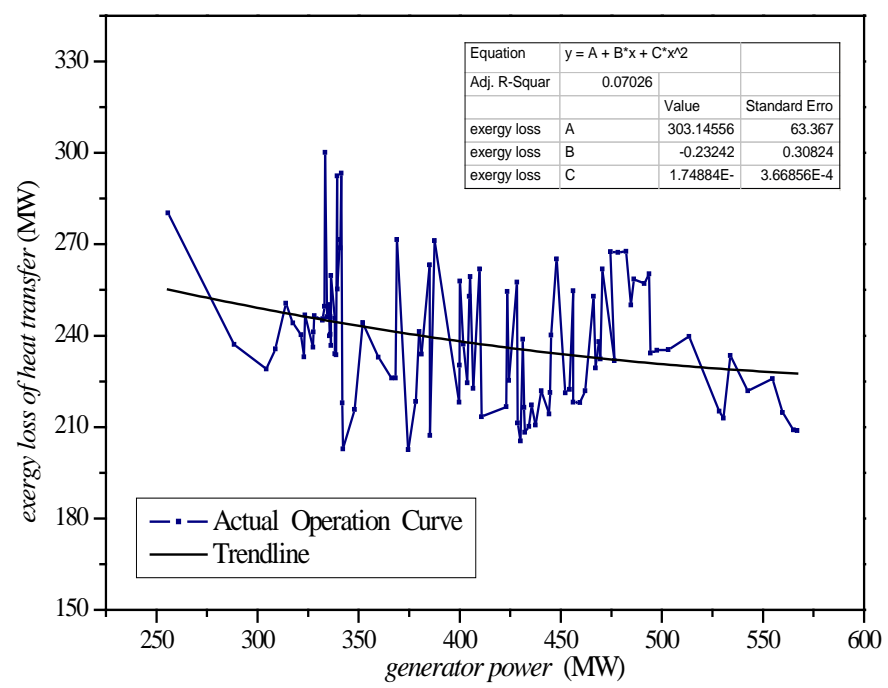

(g)

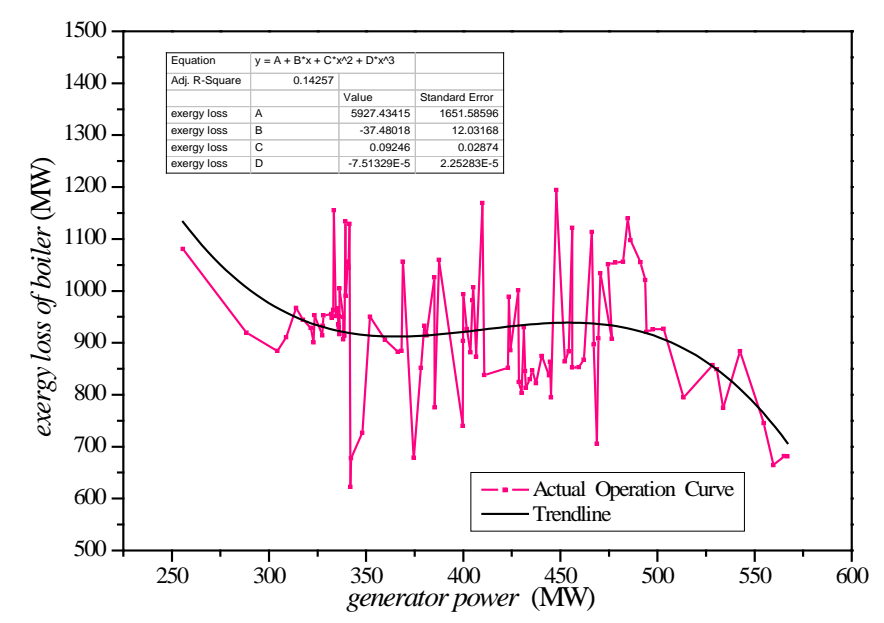

(h)

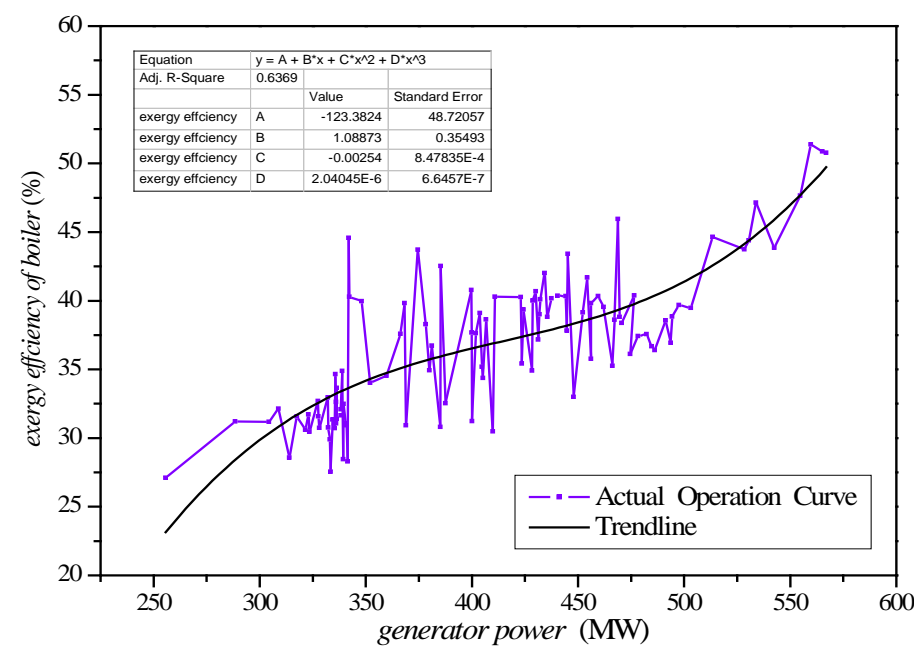

(i)

Figure 10. Exergy analysis of the boiler. (a) Exergy loss of smoke exhaust; (b) exergy loss of chemical factor; (c) exergy loss of mechanical factor; (d) exergy loss of heat dissipation; (e) exergy loss of boiler ash; (f) exergy loss of combustion; (g) exetgy loss of heat transfer; (h) exergy loss of boiler; (i) exergy efficiency of boiler. 


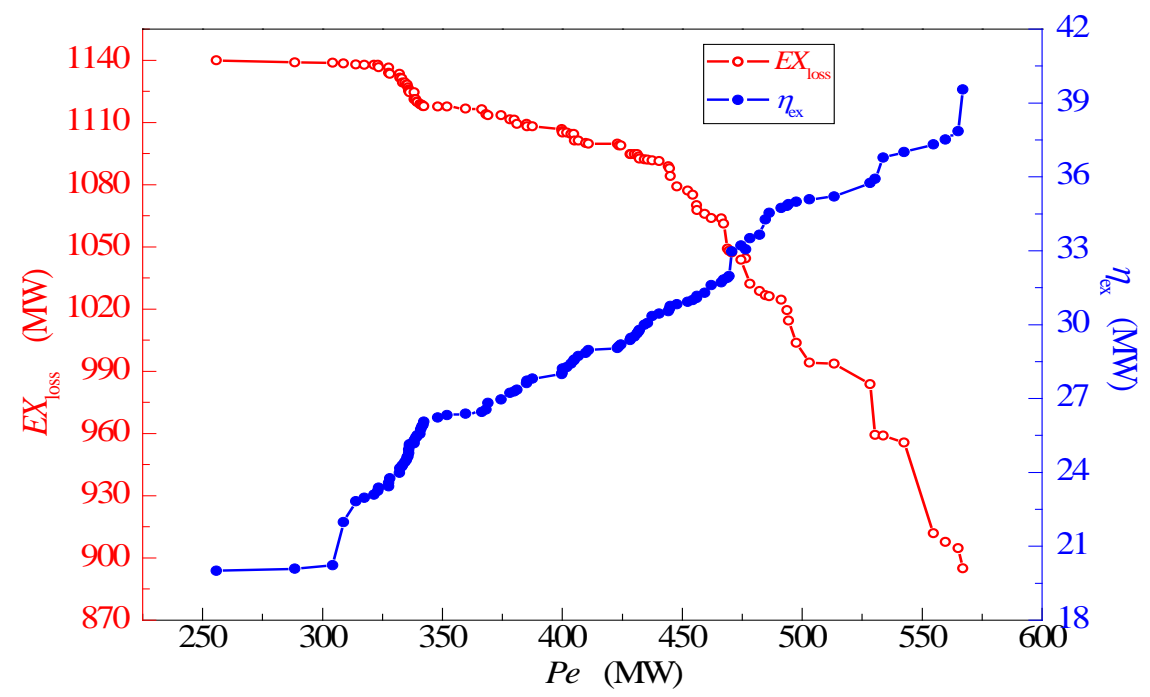

Figure 11. Total exergy loss and exergy efficiency.

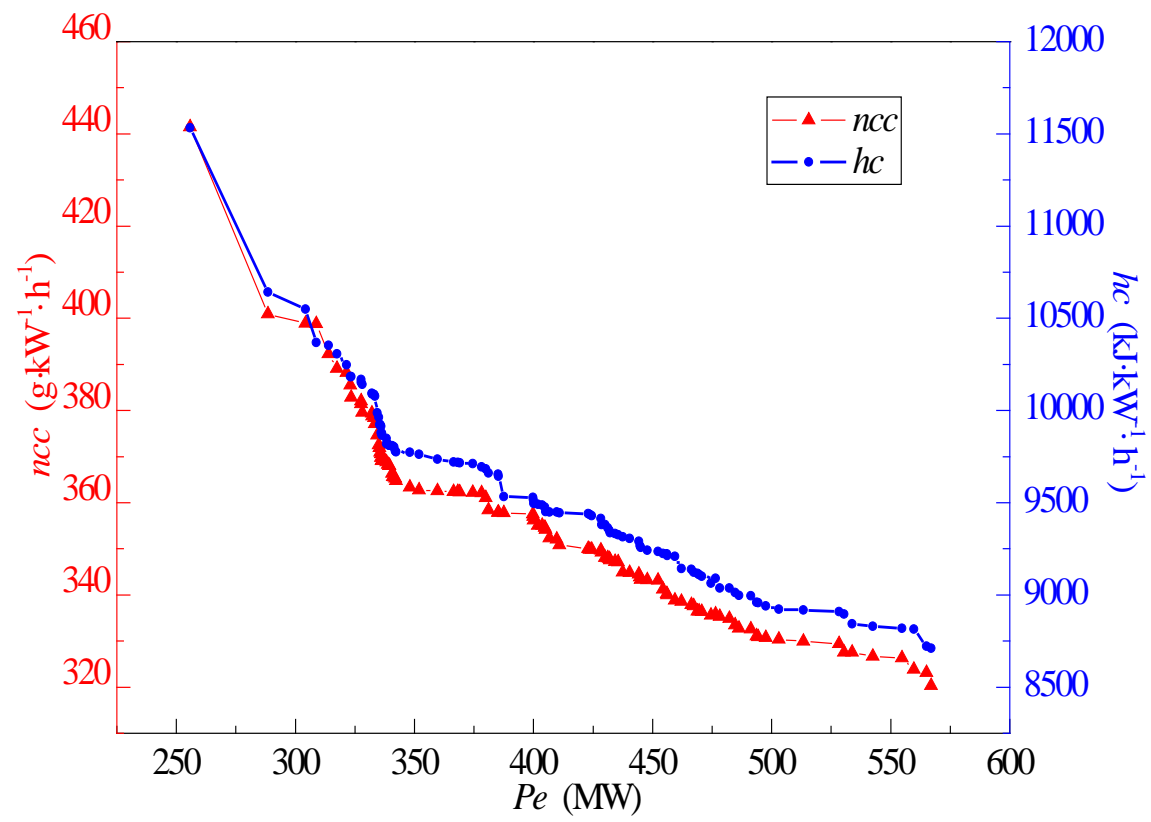

Figure 12. Heat and net coal consumption.

decreasing from $550 \mathrm{MW}$ to $350 \mathrm{MW}$, the heat and net coal consumption increases from $8965.3 \mathrm{~kJ} \cdot \mathrm{kW}^{-1} \cdot \mathrm{h}^{-1}$ to $9893.4 \mathrm{~kJ} \cdot \mathrm{kW}^{-1} \cdot \mathrm{h}^{-1}$, and from $327.3 \mathrm{~g} \cdot \mathrm{kW}^{-1} \cdot \mathrm{h}^{-1}$ to $368.2 \mathrm{~g} \cdot \mathrm{kW}^{-1} \cdot \mathrm{h}^{-1}$, respectively. Therefore, in order to improve the performance of the whole system, it is advised that the unit should run at load more than $350 \mathrm{MW}$.

\section{Conclusions}

Energy analysis and exergy analysis method have been used in this paper, combined with the most widely uses in the actual operation of $600 \mathrm{MW}$ direct dry cooling power system, a comprehensive tracking of the process of the operation condition with the full load has been carried out. The particular calculation, 
analysis and discussion of the evaluation index of the energy utilization have been given through the establishment of the whole thermal system based on the logistics process, the exergy flow processes, and thermal analysis model. And we get the following main conclusions.

1) The principal part of the exergy loss in the whole system is the boiler among which the ratio of the exergy loss is more than $70 \%$ at each operating load. The exergy losses of the combustion with the ratio of the exergy loss more than $50 \%$ are the main parts of the boiler system. Therefore, the decrease of the combustion and the heat transfer loss is the key to the energy saving for the thermal power plant.

2) The exergy of the steam turbine and the air cooling system is almost the same with the ratio of the exergy loss in the total system is about $10 \%$ both. The exergy efficiency of the steam turbine is $80 \%$ or so. Nevertheless the exergy efficiency of the air cooling system is quite low which just about $5.7 \%$ at the load rate $85 \%$. So the potential for energy saving of the air cooling system is considerable.

3) The heat and net coal consumption have similar decreasing trend with load increment. When the load is less than $350 \mathrm{MW}$, both the heat and net coal consumption shows the sharp increase with the load decreasing. And when the load is more than $350 \mathrm{MW}$, the heat and the net coal consumption increase linearly and gently with the load decreasing. Meanwhile, the exergy efficiency of the whole system decreases with the constant speed with the load decreasing. Therefore, in order to improve the performance of the whole system, it is advised that the unit should run at the load better than $350 \mathrm{MW}$.

According to the characteristics of thermal power generation and the energy consumption law of the actual thermal operation, we will continue doing the subsequent work that includes the research on the unreasonable links and the high exergy consumption processes based on the results of this paper, in order to research the lifecycle of the thermal power system and analysis the whole process of energy system from the proposed thermal economics point of view.

\section{Acknowledgements}

The Project Supported by National Natural Science Foundation of China No. 51274224.

\section{References}

[1] Zhu, M.S. (1988) Exergy Analysis of the Energy System. Tsinghua University Press, Beijing, 12-148.

[2] Lawrence, R. (2001) Advanced Coal-Fired Power Plants of Energy Resources Technology. Transactions of the ASME, 123, 4-9.

[3] Ni, W.D., Xu, X.D. and Li, Z. (1996) Some Problems of the Model and Control in Thermodynamic System. Science Press, Beijing, 1-30.

[4] Mikulandrić, R., Lončar, D., Cvetinović, D. and Spiridon, G. (2013) Improvement of Existing Coal Fired Thermal Power Plants Performance by Control Systems Modifications. Energy, 57, 55-65. 
[5] Hoffmann, B., Häfele, S. and Karl, U. (2013) Analysis of Performance Losses of Thermal Power Plants in Germany-A System Dynamics Model Approach Using Data from Regional Climate Modelling. Energy, 49, 193-203.

[6] Atmaca, E. and Basar, H.B. (2012) Evaluation of Power Plants in Turkey Using Analytic Network Process (ANP). Energy, 44, 555-563.

[7] Blanco, J.M., Vazquez, L. and Peña, F. (2012) Investigation on a New Methodology for Thermal Power Plant Assessment through Live Diagnosis Monitoring of Selected Process Parameters; Application to a Case Study. Energy, 42, 170-180.

[8] Rezaee, M.J., Moini, A. and Makui, A. (2012) Operational and Non-Operational Performance Evaluation of Thermal Power Plants in Iran: A Game Theory Approach. Energy, 38, 96-103.

[9] Blanco-Marigorta, A.M., Sanchez-Henríquez, M.V. and Peña-Quintana, J.A. (2011) Exergetic Comparison of Two Different Cooling Technologies for the Power Cycle of a Thermal Power Plant. Energy, 36, 1966-1972.

[10] Liao, C.H., Ertesvåg, I.S. and Zhao, J.N. (2013) Energetic and Exergetic Efficiencies of Coal-Fired CHP (Combined Heat and Power) Plants Used in District Heating Systems of China. Energy, 57, 671-681.

[11] Xu, G., Yang, Y.P., Ding, J., Li, S.C., Liu, W.Y. and Zhang, K. (2013) Analysis and Optimization of $\mathrm{CO}_{2}$ Capture in an Existing Coal-Fired Power Plant in China. Energy, 58, 117-127.

[12] Restrepo, Á., Miyake, R., Kleveston, F. and Bazzo, E. (2012) Exergetic and envIronmental Analysis of a Pulverized Coal Power Plant. Energy, 45, 195-202.

[13] Dios, M., Souto, J.A. and Casares, J.J. (2013) Experimental Development of $\mathrm{CO}_{2}$, $\mathrm{SO}_{2}$ and $\mathrm{NO}_{\mathrm{x}}$ Emission Factors for Mixed Lignite and Subbituminous Coal-Fired Power Plant. Energy, 53, 40-51.

[14] Bekat, T., Erdogan, M., Inal, F. and Genc, A. (2012) Prediction of the Bottom Ash Formed in a Coal-Fired Power Plant Using Artificial Neural Networks. Energy, 45, 882-887.

[15] Bi, M.S. (2001) Engineering Thermodynamics. Chemical Industry Press, Beijing, 20-98.

[16] Guo, M.Y. (2001) Research and Development in the Area of Analysis Methods for Power Plants Thermodynamic Systems. Thermal Power Generation, 1, 7-10.

[17] Isam, H. (2009) Energy and Exergy Analysis of a Steam Power Plant in Jordan. Applied Thermal Engineering, 29, 324-328.

[18] Kwak, H.Y., Kim, D.J. and Jeon, J.S. (2003) Exergetic and Thermoeconomic Analysis of Power Plants. Energy, 28, 343-360.

[19] Tapan, K.R., Amitava, D. and Getal, A. (2010) Exergy-Based Performance Analysis for Proper O\&M Decisions in a Steam Power Plant. Energy Conversion and Management, 51, 1333-1344.

[20] Zuhal, O. (2009) Investigation of Coal-Fired Power Plants in Turkey and a Case Study: Can Plant. Applied Thermal Engineering, 29, 550-557.

[21] Mehmet, K., Ibrahim, D. and Marc, A.R. (2007) Understanding Energy and Exergy Efficiencies for Improved Energy Management in Power Plants. Energy Policy, 35, 3967-3978.

[22] Zhang, X.H., Yang, M. and Mei, L. (2004) Research on Exergy Analysis Computation of Coal Fired Unit Thermal System. Power Engineering, 24, 703-706.

[23] Ahern, J.E. (1984) Method of the Exergy Analysis of the Energy System. China Machine Press, Beijing, 53-163. 
[24] Rosen, M.A. (2001) Energy- and Exergy-Based Comparison of Coal-Fired and Nuclear Steam Power Plants. International Journal of Exergy, 3, 180-192.

[25] Suresh, M.V.J.J., Reddy, K.S. and Ajit, K.K. (2006) Energy and Exergy Analysis of Thermal Power Plants Based on Advanced Steam Parameters. National Conference on Advances in Energy Research, India, 4-5 December 2006, IITB.

[26] Sengupta, S., Datta, A. and Duttagupta, S. (2007) Exergy Analysis of a Coal-Based 210 MW Thermal Power Plant. International Journal of Energy Research, 31, 14-28. https://doi.org/10.1002/er.1224

[27] Reddy, B.V. and Butcher, C.J. (2007) Second Law Analysis of a Waste Heat Recovery Based Power Generation System. International Journal of Heat and Mass Transfer, 50, 2355-2363.

[28] Ganapathy, T., Alagumurthi, N., Gakkhar, R.P. and Murugesan, K. (2009) Exergy Analysis of Operating Lignite Fired Thermal Power Plant. Journal of Engineering Science and Technology Review, 2, 123-130.

[29] Aljundi, I.H. (2009) Energy and Exergy Analysis of a Steam Power Plant in Jordan. Applied Thermal Engineering, 29, 324-328.

[30] Erdem, H.H., Akkaya, A.V., Cetin, B., Dagdas, A., Sevilgen, S.H., Sahin, B., Teke, I., Gungor, C. and Atas, S. (2009) Comparative Energetic and Exergetic Performance Analyses for Coal-Fired Thermal Power Plants in Turkey. International Journal of Thermal Sciences, 48, 2179-2186.

[31] Oktay, Z. (2009) Investigation of Coal-Fired Power Plants in Turkey and a Case Study: Can Plant. Applied Thermal Engineering, 29, 550-557.

[32] Naterer, G.F., Regulagadda, P. and Dincer, I. (2010) Exergy Analysis of a Thermal Power Plant with Measured Boiler and Turbine Losses. Applied Thermal Engineering, 30, 970-976.

[33] Yan, S.L., Hu, S.G. and Xu, H. (2008) General Physical Model and Solution of Equations Distribution of Steam-Water for the Regenerative System in Thermal Power Plant. Power engineering, 28, 480-486.

[34] Cheng, L.W., Chen, D.H. and Xu, S.C. (2004) Thermoeconomic Analysis of Power Plants. Power Engineering, 24, 580-583.

[35] Shen, W.D., Jiang, Z.M. and Tong, J.G. (2001) Engineering Thermodynamics. Higher Education Press, Beijing.

[36] Li, Y.H., Sun, G. and Qiu, Y.G. (2009) Exergy Efficiency Analysis of the Power Plant. Boiler technology, 40, 27-30.

[37] Fu, Q.S. (2005) Method of Thermodynamics Analysis of the Energy System. Xi'an Jiaotong University Press, Xi'an, 50-129.

[38] Rao, A.D. (2001) A Thermodynamic Analysis of Tubular SOFC based Hybrid Systems. Doctoral Thesis, University of California, Oakland, CA. 
Submit or recommend next manuscript to SCIRP and we will provide best service for you:

Accepting pre-submission inquiries through Email, Facebook, LinkedIn, Twitter, etc. A wide selection of journals (inclusive of 9 subjects, more than 200 journals)

Providing 24-hour high-quality service

User-friendly online submission system

Fair and swift peer-review system

Efficient typesetting and proofreading procedure

Display of the result of downloads and visits, as well as the number of cited articles Maximum dissemination of your research work

Submit your manuscript at: http://papersubmission.scirp.org/

Or contact epe@scirp.org 